\title{
Research Paper: Relationship Between Social Sup- port and Coping Strategies and Disease Among the Cancer Patients of the City of Kerman
}

\author{
Soodeh Maghsoodi ${ }^{*}$ (D, Zahra Salehinejad ${ }^{1} \mathbb{D}$ \\ 1. Department of Social Sciences, Faculty of Literature and Humanities, Shahid Bahonar University of Kerman, Kerman, Iran.
}

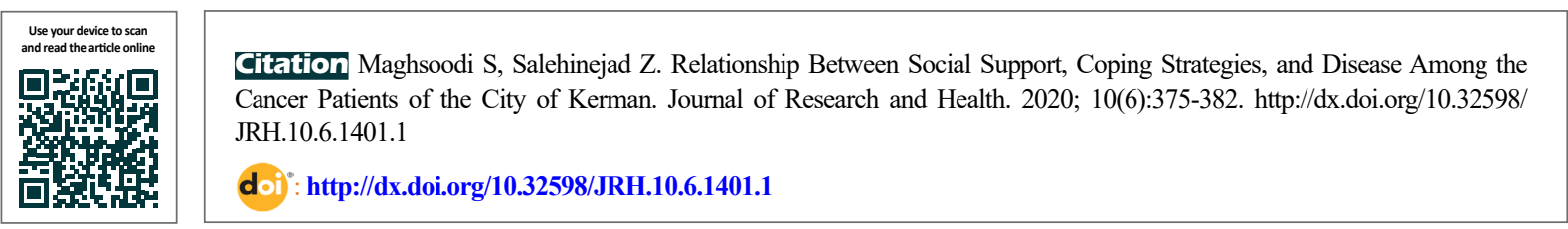

\section{(i) (8)}

Article info:

Received: 17 May 2018

Accepted: 03 Aug 2019

Publish: 01 Nov 2020

\section{Keywords:}

Cancer, Social support, Coping strategy

\section{ABSTRACT}

Background: Cancer pain affects coping strategies in patients. Besides, social protection is a tool that helps to alter the patient's encounter with cancer. This study aimed to investigate the relationship between social support, coping, and disease strategies.

Methods: This was an analytical cross-sectional study with a quantitative approach, and conducted using a self-made social support questionnaire and the Billings and Mouse coping strategies questionnaire. The study population consisted of all the cancer patients in Kerman City, from September 2016 to March 2017; it was estimated to include 1400 people. Based on the Cochran formula, the study sample size was calculated as 300 cancer patients, which were collected using a systematic sampling method. Also, data analysis was carried out using the Pearson tests and regression in SPSS V. 21.

Results: The results showed a statistically significant association of social support and coping with the disease strategies $(\mathrm{P}<0.01)$. Moreover, problem-focused coping has the most positive and direct relationship with social support. Regression analysis also showed that emotional aspects (kindness and shared positive actions), service-practical support, and financial support can predict the coping strategies with disease.

Conclusion: According to the results, it is recommended to formulate a comprehensive care program and increase social support to enhance the problem-focused coping strategies among cancer patients.

\section{Introduction}

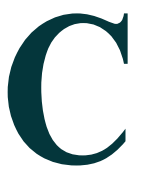

ancer is one of the major health problems, the third cause of death, and the second noncommunicable chronic disease worldwide [1]. According to the World Health Organization reports, cancer-consequent deaths were nine million people in 2015 and will reach 11.4 million in countries with low or middle income in 2030 ; ie, over $70 \%$ of death incidents. In our country, The annual incidence of cancer is about 70000 , which is about 98 people daily [2, 3]. Cancer disrupts the occupation, socioeconomic status, and family

\section{* Corresponding Author:}

Soodeh Maghsoodi, PhD.

Address: Department of Social Sciences, Faculty of Literature and Humanities, Shahid Bahonar University of Kerman, Kerman, Iran.

Phone: +98 (913) 3975368

E-mail:smaghsoodi@uk.ac.ir 
life and sometimes destruct people's life. These effects influence various aspects of life, including mental health and psychological, social, economic, and sexual functions [4]. During illness, cancer patients endure several pressures that affect their coping strategies. So, coping strategy is an important factor in the patients' lives. Coping strategy should be considered and factors that influence it should be identified. One of these factors is social support from people, such as family, friends, relatives, physicians, and the others of these patients [5].

Social support facilitates the tolerance of life difficulties for families and patients and is known as the greatest defensive force for successful and easy coping, in stressful conditions and the time of struggling with disease [6]. Social protection is a situation that others provide for people to make them feel cared for, loved, valued, and self-esteem and cause them to feel that they are a part of a vast communication network that able them to cope well with stressful factors. Researchers tried to define social support through the actions and behaviors of others, the functions of these actions, and what people received from these actions to adequately conceptualize social support and give meaning to conflicting theoretical structures [7]. Cancer increases the need for social supports because it changes the patients' lives and tolerance methods [8]. Support from the others of the people with cancer neutralizes the negative consequences of disease and treatment and is strongly related to the mental health and coping methods of the patients [9].

Humans always try to adapt to unpleasant events or cope along with them, but coping strategies differ in different people and situations [10]. "In fact, coping strategies are a series of cognitive and behavioral efforts of a person that are using for interpretation and modification of a stressful situation and coping with problems and has a basic and determinative role in physical and mental health. Effective coping strategies reduce individual reaction to higher levels of stress and adjusted its harmful effects" [11]. Studies show that cancer patients differently react to their illness as a change in their lives, and differently tolerate the harmful effects of the disease. The method of disease tolerance can be problem-focused [4] or emotion-focused [5]. In the problem-focused method, the person acts directly and face-to-face, based on the stressful position, to adjust the stressful factor and finally reach the goal. Conversely, the emotion-focused method is done through a cognitive-behavioral approach to control and curb the effects of stressful emotional situations [12]. However, the method chosen by patients is influenced by social support from the others [13]
Coping with illness strategies and social support are strongly dependent on each other $[14,15]$. The results of some studies in Iran and other countries indicate a significant relationship between social support and the methods of coping with disease [10, 16-29]. For example, Shoaakazemi et al. reported a positive and significant relationship between the amount of social support received from family and problem-focused coping methods [5]. Also, Kalbfleisch et al. concluded that patients with higher levels of social support showed higher scores in adaptive tolerance, compared with patients with lower levels of social support [30].

A few studies have been conducted in the field of coping with disease strategies, considering cancer patients. Also, comprehensive studies can rarely be found in social protection and its effect on the tolerance methods of cancer patients. However, the number of cancer patients is increasing daily. According to the latest statistical studies in Iran, cancer is the third major cause of death after cardiovascular diseases and unintentional injuries. Annually, more than 30000 people lost their lives owing to this disease, in the country. Also, it is estimated that more than 70 000 new cases of cancer are diagnosed annually [31, 32]. Moreover, Kerman province has a high record of cancer.

According to statistics, each year between 2500 to 3000 people get various kinds of cancers, in Kerman province. Although some important types of cancer in the country, such as esophagus, stomach, mouth, and colon cancers have a lower incidence in Kerman province, some neoplasms, such as leukemia and liver, lung, breast, and prostate cancers have a higher incidence than the national average and infect a considerable number of people every year [33]. These patients experience the psychological and social consequences of cancer and face a lot of problems in the absence of social support and coping strategies.

Social support is an important factor in the lives of cancer patients and impacts disease tolerance. Thus, this study evaluates the relationship between social support and disease tolerance, among cancer patients, in Kerman City. This study mainly aimed to investigate the relationship between social support and disease tolerance among cancer patients.

\section{Methods}

The present study was a correlational research with a crosssectional design. Survey data were collected using questionnaires and interviews with respondents. A researcher-made questionnaire was used to measure social support. 
The developed questionnaire consisted of two parts (social support and disease tolerance methods). The social support questionnaire consisted of 22 terms and four general subscales, including emotional support, service-practical support, information support, and financial support. Also, emotional support consisted of three subscales of empathy, kindness, and shared positive activity. The social support questionnaire developed by Sherbourne and Stewart [34] and the Garoosi questionnaire [35] were used to develop this researcher-made questionnaire. This self-report tool measures respondents' disagreement or agreement on a 5-point Likert scale (1: Never, 2: Rarely, 3: Sometimes, 4: More often, and 5: Always). The lowest and highest scores in this test are 22 and 110, respectively. Besides, all points are aggregated to get the overall score. Subjects with high scores on the scale receive good social support.

Billings and Mouse tolerance inventory was used to measure disease tolerance. In 1984, Billings and Moss developed this questionnaire to examine how people respond to stressful events. The questionnaire includes 19 items scored on a 4-point Likert scale (from 1: Never, to 4: Always). This questionnaire includes two types of problem-focused and emotion-focused tolerances. The maximum score of the subjects in this questionnaire is 76 , which includes the maximum scores of 44 and 32 on the options of problematic tolerance and emotional tolerance, respectively.

The study population consisted of all cancer patients in Kerman. The number of these patients ranged from 2500 to 3000 during a year, and in the semester it was estimated to be 1400 , based on the preliminary studies, patient statistics from chemotherapy clinics, the Association of Cancer Patients of Kerman province, and the health development document [33]. Considering the statistical population, the study sample size was calculated as 300 , based on the Cochran formula. A physician announced the definitive diagnosis of the disease in participants.

The study sample was recruited using a systematic sampling method; patients who were referred to the treatment centers were selected according to their names in the relevant list. The researcher regularly referred to the Oncology Department of the Bahonar Hospital, the Chemotherapy Department of Javad Al-Aeme Special Disease Center, and the Yas Association on various days of the week. Then, she selected the participants and assured them about data confidentiality and observing all ethical considerations. Next, she completed the study questionnaires, based on the participants' information and interviews.
Initially, the validity and reliability of the study questionnaires were assessed. Validity refers to the accuracy of indicators and criteria developed to measure the phenomenon in questions [36]. The main method of validity testing is to carefully examine the conceptual measure in the light of its meaning and to ask the question of whether the measuring instrument really measures the concept in question. This type of attention and scrutiny is called the face validation method [37]. After drafting the questionnaire, it was evaluated by university professors and several sociologists in the field of health to identify and resolve its shortcomings and disadvantages (in terms of incomprehensibility, ambiguity, etc.).

Then, some questions were corrected and formulated in a written questionnaire. Also, the internal consistency method was used to measure data reliability. The most important indicator of internal agreement is the Cronbach alpha test. The Cronbach alpha value fluctuates between zero and one. This value was greater than 0.7 in all dimensions of the used questionnaires. Then, data were collected using the questionnaires and prepared for extraction and processing. For this purpose, the questionnaires were coded and matched. The obtained data were analyzed using descriptive and inferential statistics in SPSS. Descriptive statistics were reported as frequencies, percentages, averages, and standard deviations. In inferential analyses, the Pearson tests and multiple regression analysis were used to predict the dependent variable, according to the level of study variables.

\section{Results}

Based on descriptive statistics, the mean age of the respondents was 47.80 years. Out of 300 respondents, 184 people $(61.3 \%)$ were female and 116 people $(38.7 \%)$ were male. Also, 39 people (13\%) were single and 261 people $(87 \%)$ were married. Most respondents have housework (139 people, $46.3 \%$ ) and a high school diploma (79 people, $26.3 \%$ ). Furthermore, most respondents (249 people, 83\%) were earning less than two million Tomans per month. More than half of the respondents (166 people, 55.3\%) were residing in Kerman City. Also, breast cancer was the most prevalent diagnosis (79 Cases, 26.3\%); most respondents (114 cases, 38\%) had received cancer diagnosis less than one year ago.

\section{Status of the social support and the dimensions of disease tolerance methods}

The social support variable is composed of emotional components (empathy, kindness, and doing positive joint activities), service-practical support, information 
Table 1. Social support variable frequency in the study sample

\begin{tabular}{cccc}
\hline & Items & No. (\%) & CF (\%) \\
\hline & Never & $9(3.0)$ & 3.0 \\
& Rarely & $34(11.3)$ & 14.3 \\
Social support & Sometimes & $65(21.7)$ & 36.0 \\
& More often & $75(25.0)$ & 61.0 \\
& Always & $117(39.0)$ & 100.0
\end{tabular}

Table 2. Frequency of problem-focused and emotion-focused tolerance methods

\begin{tabular}{lccc}
\hline & & No. (\%) & CF (\%) \\
\hline & Never & $12(4.0)$ & 4.0 \\
Sometimes & $106(35.4)$ & 39.3 \\
Emotion-focused & More often & $121(40.3)$ & 79.7 \\
& Always & $61(20.3)$ & 100.0 \\
Total & Never & $300(100.0)$ & 5.3 \\
Problem-focused & Sometimes & $210(5.3)$ & 75.3 \\
& More often & $66(22.0)$ & 97.3 \\
\hline
\end{tabular}

IPRA

support, and financial support. From these components, social support score was obtained among 300 surveyed people; most of them have always had social support (Table 1). According to Table 2, most people often use problem-focused tolerance. The results also show that most people sometimes use emotion-focused tolerance.

According to Table 3, the service-practical component of social support and after that problem-focused tolerant dimension have the highest mean values among the other components.

The relationship between social support and the dimensions of disease tolerance (problem-focused and emotion-focused tolerances) is measured among cancer patients in Kerman. Table 4 indicates the correlation coefficients between the independent variable (social sup- port) and the dimensions of the dependent variable (the disease tolerance methods). There is a positive and direct relationship between social support and the dimensions of disease tolerance, in cancer patients $(\mathrm{P}<0.01)$. Also, social support has more influence on problem-focused than emotion-focused methodology, in other words, problem-oriented tolerance has the most positive and direct relationship with social support.

This section examines the relationship between the types of social support (emotional support [empathy, kindness, and shared positive activity], service-practical support, information support, and financial support) and disease tolerance methods, among the cancer patients. The stepwise regression analysis (with 4 steps) was used to identify the most influential components of social support on disease tolerance (Table 5). The variables of emotional support 
Table 3. Mean $\pm S D$ of independent and dependent variables and their subscales $(N=300)$

\begin{tabular}{ccc}
\hline \multicolumn{2}{c}{ Variables } & Mean \pm SD \\
\hline Kindness & $15.15 \pm 4.37$ \\
Social support & Doing positive joint activities & $10.97 \pm 3.57$ \\
& Service-practical support & $10.99 \pm 4.46$ \\
& Information support & $19.99 \pm 5.34$ \\
& Financial support & $15.21 \pm 4.25$ \\
Dimensions of disease & Total social support & $11.06 \pm 3.98$ \\
tolerance & Problem-focused & $83.51 \pm 21.95$ \\
\hline
\end{tabular}

MRE

Table 4. Pearson correlation coefficient matrix between the social support and the dimensions of disease tolerance $(\mathrm{N}=300)$

\begin{tabular}{|c|c|c|c|c|}
\hline Variables & & Social Support & Problem-focused & Emotion-focused \\
\hline \multirow{3}{*}{ Social support } & $r$ & 1 & $0.392 * *$ & $0.241^{* *}$ \\
\hline & & & & \\
\hline & $\mathrm{P}$ & & 0.000 & 0.000 \\
\hline \multirow{3}{*}{ Problem-focused } & $r$ & $0.392 * *$ & 1 & $0.541^{* *}$ \\
\hline & & & & \\
\hline & $\mathrm{P}$ & 0.000 & & 0.000 \\
\hline \multirow{3}{*}{ Emotion-focused } & $r$ & $0.241 * *$ & $0.541^{* *}$ & 1 \\
\hline & & & & \\
\hline & $\mathrm{P}$ & 0.000 & 0.000 & \\
\hline
\end{tabular}

** Correlation is significant at the 0.01 level (2-tailed).

Table 5. Regression analysis of the types of social support and disease tolerance methods

\begin{tabular}{|c|c|c|c|c|c|c|c|c|}
\hline 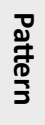 & Order & Predictive Variables & $\begin{array}{l}\text { Multiple } \\
\text { Correlation } \\
\text { Coefficient }\end{array}$ & $\begin{array}{l}\text { Squared Multi- } \\
\text { ple Correlation } \\
\text { Coefficient }\end{array}$ & $\begin{array}{l}\text { Modified Squared } \\
\text { Multiple Correla- } \\
\text { tion Coefficient }\end{array}$ & $\begin{array}{l}\text { Standard Error } \\
\text { Estimation }\end{array}$ & $\begin{array}{l}\text { F Coef- } \\
\text { ficient }\end{array}$ & $\mathbf{P}$ \\
\hline \multirow{4}{*}{$\begin{array}{l}\frac{n}{0} \\
\frac{1}{0} \\
\frac{0}{2} \\
\frac{n}{0} \\
\frac{10}{0}\end{array}$} & 1 & $\begin{array}{l}\text { Emotional support } \\
\text { (kindness) }\end{array}$ & 0.378 & 0.143 & 0.140 & 7.60 & 49.17 & 0.000 \\
\hline & 2 & $\begin{array}{l}\text { Emotional support } \\
\text { (kindness) }+ \text { financial } \\
\text { support }\end{array}$ & 0.413 & 0.171 & 0.165 & 7.48 & 30.28 & 0.000 \\
\hline & 3 & $\begin{array}{l}\text { kindness }++ \text { Financial } \\
\text { support } \\
\text { doing positive joint ac- } \\
\text { tivities }\end{array}$ & 0.427 & 0.182 & 0.174 & 7.44 & 21.79 & 0.000 \\
\hline & 4 & $\begin{array}{l}\text { kindness + + Financial } \\
\text { support } \\
\text { doing positive joint ac- } \\
\text { tivities + service-practi- } \\
\text { cal support }\end{array}$ & 0.442 & 0.195 & 0.184 & 7.40 & 17.72 & 0.000 \\
\hline
\end{tabular}


(kindness), financial support, emotional support (doing positive joint activities), and service-practical support were entered into the prediction equation in the first, second, third, and fourth steps, respectively. Then, the emotional support (empathy) and information support variables were excluded from the equation because they had little or no relationship with disease tolerance methods.

\section{Discussion}

The present study investigated the relationship between social support and disease tolerance, in cancer patients. The results showed a statistically significant relationship between social support and the dimensions of coping with disease.

Moreover, the results showed a positive and direct relationship between social support and problem-focused tolerance; this type of coping strategy had the most positive and direct relationship with social support. As social support increases, the strength and the skill of using problem-focused tolerance increase, thereby, the likelihood of disease recurrence reduces. This finding is in line with the results of Shoaakazemi et al. [5], Hassanzadeh et al. [38], Narimani [39], Tan and Karabulutlu [40], and Kalbfleisch et al. [30]. So that, there was a positive relationship between social support and problem-focused tolerance. Also, it was found a positive and direct relationship between social support and emotion-focused coping. Tan and Karabulutlu [40] reported a negative relationship between social support and emotion-focused tolerance, while the present study found a positive relationship between these two variables.

Besides, the variables of emotional support (kindness and shared positive activity), service-practical support, and financial support predicted the disease tolerance. In other words, actions, such as expressing love, affection, and friendship; having fun and engaging activities; and providing material assistance and behavioral assistance can anticipate the ways of coping with the disease.

Two models of social support can be proposed to explain the above findings. Research has examined the impact of these two models, namely, the direct and shield-like effects of social support on psychological and physical health. The direct effect model assumes that social support increases one's health and psychological well-being regardless of the stress level. The shield-like model argues that in the presence of adverse events, social protection protects individuals from the pathogenic effects of stress. The results of this study that show the predictive and prominent role of support in problem-focused tolerance, in cancer patients, support both models of social support.
Patients receiving the most out of these supports from people around them can use problem-focused tolerance techniques and effectively and rationally adapt to environmental stresses caused by the disease (direct effect model). On the other hand, if these patients receive social support, their stress will be greatly reduced and they will be able to reasonably and effectively tolerate the stress. This support acts as a protective shield against disease-induced stress (shield-like model). On the other side, social support makes people feel cared for, loved, self-esteem, and valued and causes them to feel that they are a part of a vast communication network, which able them to cope well with stressful factors [38].

Studies have shown a significant relationship between social support and health. In the presence of friends and acquaintances, the physiological responses to stress are less than when the individuals are alone. Considering the social support and its components as the predictors of tolerance, if these patients receive social support (especially family and others support), the degree of disease stress will be reduced; this change will affect their logical coping strategy.

Based on the present results, some recommendations are provided as follows: informing cancer patients and their relatives (especially the members of patients' families), using media, compiled advertising, and training sessions about the significant and important role of social support and its effects on disease tolerance; teaching problem-focused tolerance and how to cope with illness to cancer patients; holding training sessions on the effects of social support on the lives of cancer patients for health care staff; clarifying the important role of treatment staff in transferring these trainings to patients and their companions; and using NGOs to support cancer patients and their surroundings and provide services, such as donations, creating fun and enjoyable programs, camps, etc. to boost patients morale and incense the problem-focused tolerance rather than emotion-focused type.

There were some limitations and challenges in this research. This was a cross-sectional study and data were collected at a specific time point. Also, the use of questionnaires for acquiring information includes some problems and limitations. The present study only involved cancer patients in Kerman City; this fact limits the ability to extend the findings to other groups and communities, limiting the external validity of the study. Also, the lack of Persian research and theoretical literature on the subject under study along with limited access to credible sources were the serious limitations of this study. 


\section{Conclusion}

Overall, social support is one of the most important external resources that can be used by cancer patients to overcome illness and cope with psychosocial and economic imbalances. Based on the results, it is recommended to develop a comprehensive care plan for cancer patients to increase social support for choosing problemfocused tolerance.

\section{Ethical Considerations}

\section{Compliance with ethical guidelines}

The study was Ethically approved By the Shahid Bahonar University of Kerman, Kerman, with No. 99/121544, on July 14, 2020.

\section{Funding}

The paper was extracted from the MSc. thesis of the second author, Department of Social Sciences, Faculty of Literature and Humanities, Shahid Bahonar University of Kerman

\section{Authors' contributions}

All authors equally contributed in preparing this article.

\section{Conflict of interest}

The authors declared no conflict of interest.

\section{Acknowledgments}

The authors thank all the patients who participated in this project, as well as all the staff of the oncology ward of Bahonar Hospital and the Chemotherapy Department of the Javad-al-a'emeh Special Diseases Center and the Yas Association.

\section{References}

[1] Jemal A, Bray F, Center MM, Ferlay J, Ward E, Forman D. Global Cancer Statistics. CA Cancer J Clin. 2011; 61(2):69-90. [DOI:10.3322/caac.20107] [PMID]

[2] Vafajo Diantai Z, Abedini Z, Ahmari Tehran H, Mohamad Gholizade L. [Epidemiology of cancer in Qom (Persian)]. Payesh. 2014; 13(2):155-63. http://payeshjournal.ir/article1-310-fa.html
[3] Safari N, Kavosi A, Jouybari L, Sanagoo A, Mohammadi GH. [The relationship between catastrophizing, pain-related anxiety and coping strategies in cancer patients (Persian)] IJPN. 2015; 3(2):31-42. http:/ /ijpn.ir/article-1-564-fa.htm

[4] Shaban M, Monjamed Z, Mehran A, Hasanpour Dehkordi A [The relation between the cancer characteristics and quality of life in the patients under chemotherapy (Persian)]. Hayat. 2004 10(3):79-84. http:/ / hayat.tums.ac.ir/article-1-261-fa.html

[5] Shoaakazemi M, Haggani S, Saadati M, Khajehvand A. [Relation between family social support \& coping strategies in recovery breast cancer (Persian)]. Int J Behav Dev (IJBD). 2014 6(4):35-40. http://ijbd.ir/article-1-306-fa.html

[6] Heidari S. [The relationship between social support and quality of life among cancer patients referred to medical sciences universities selected hospitals of Tehran and Iran (Persian)] [MSc. thesis]. Tehran: Iran University of Medical Sciences; 2005

[7] Neshat R. [Predict life satisfaction based on attitudes to gender roles and social support (Persian)] [MSc. thesis]. Kerman Shahid Bahonar University of Kerman; 2013.

[8] Heidari S. [Assessing size of social network and emotional support sources and related factors among cancer patients (Persian)]. Iran J Nurs Res (IJNR) . 2009; 4(12-13):91-101. http://ijnr.ir/article-1-384-fa.html

[9] Lotfi Kashani F, Taheri A, Mirzaee H, Masoudi Moghaddam Z. [Relationship between social support and self-esteem with depression and anxiety in cancer patients (Persian)]. J Social Psychology. 2012; 8(25):101-15. https://www.sid.ir/fa/journal/ViewPaper.aspx?id=220986

[10] Ghazanfari F, Ghadampoor E. [The relationship between mental health and coping strategies in citizenshipofKhoramabad city (Persian)]. J Fundame Mental Health. 2008; 10(37):47-54. [DOI: 10.22038/JFMH.2008.1775]

[11] Farzin Rad B, AsgharnejadFarid AA, YekkeYazdandoost R, HabibiAsgarabad M. [Comparison of copying strategies and personality styles in depressed and non-depressed students (Persian)]. J Res Behav Sci. 2010; 4(1):17-21. https:// www.sid.ir/fa/journal/ViewPaper.aspx?ID=104718

[12] Mansoori Z. [The causal efficacy, alexithymia, life satisfaction, affective family functioning and coping styles and Bramadgy addiction (Persian)] [MSc. thesis]. Kerman: Shahid Bahonar University of Kerman; 2012

[13] Khodayarifard M, Parand A. [Stress and methods to deal with it (Persian)]. Tehran: Tehran University Press; 2006. https://www.adinehbook.com/gp/product/9640355411

[14] Sollner W, Mairinger G, Zingg-Schir M, Fritsch P. Cancer prognosis, psychosocial stress and attitude of melanoma patients to supportive psychotherapy. Hautarzt. 1996; 47(3):200-5 [DOI:10.1007/s001050050403] [PMID]

[15] Basharpoor S, Narimani M, Essazadeghan A. [Relation between coping strategies and social support with perceived stress (Persian)]. J Educ Psychol Stud. 2013; 9(2):29-48. [DOI: 10.22051/PSY.2013.1743]

[16] Bal S, Crombez G, Van Oost P, Debourdeaudhuij I. The role of social support in well-being and coping with self-reported stressful events in adolescents.Child Abuse Negl. 2003; 27(12) 1377-95. [DOI:10.1016/j.chiabu.2003.06.002] [PMID] 
[17] Dirkzwager JE, Bramsen I, Van Der Ploeg HM. Social support, coping, life events, and post-traumatic stress symptoms among former peacekeeper: A prospective study. Pers Individ Dif. 2003; 34(8):1545-59. [DOI:10.1016/S0191-8869(02)00198-8]

[18] Zunzunegui MV, Kone A, Johri M, Beland F, Wolfson C, Bergman H. Social networks and self-rated health in two French-speaking Canadian community dwelling populations over 65. Soc Sci Med. 2004; 58(10):2069-81. [DOI:10.1016/j.socscimed.2003.08.005] [PMID]

[19] Greenglass E, Fiksenbaum L, Eaton J. The relationship between coping, social support, functional disability and depression in the elderly. Anxiety Stress Coping. 2006; 19(1):1531.[DOI:10.1080/14659890500436430]

[20] Barry LC, Kasl SV, Lichtman J, Viola V, Harlan HM. Social support and change in health-related quality of life 6 months after coronary artery bypass grafting. J Psychosom Res. 2006; 60(2):185-93.[DOI:10.1016/j.jpsychores.2005.06.080] [PMID]

[21] Lopez-Martinez AE, Esteve-Zarazaga R, Ramirez-Maestre C. Perceived social support and coping responses in pain adjustment among chronic pain patients. J Pain. 2008; 9(4):373-9. [DOI:10.1016/j.jpain.2007.12.002] [PMID]

[22] Lou Y, Wang H. Correlation research on psychological health impact on nursing students against stress, coping way and social suppor. Nurse Educ Today. 2009; 29(1):5-8. [DOI:10.1016/j.nedt.2008.05.019] [PMID]

[23] Wonderlich-Tierney AL, Vander Wal JS. The effects of social support and coping on the relationship between social anxiety and eating disorders. Eat Behav. 2010; 11(2):85-91. [DOI:10.1016/j.eatbeh.2009.10.002] [PMID]

[24] Razuel C, Bruchon-Schweitzer M, Dupanloup A, Irion O, Epiney M. Stressful events, social support and coping strategies of primiparous women during the postpartum period: A qualitative study. Midwifery. 2011; 27(2):237-42. [DOI:10.1016/j.midw.2009.06.005] [PMID]

[25] Akbari abdolabadi M, Mohebbi B, Sadeghi R, Tol A, Mahmoudi Majdabadi M. [The effect of educational intervention on barriers of living with Diabetes in awareness and belief, lifestyle, adaptation, and support dimensions among patients with type 2 Diabetes mellitus: Application of the basnef model (Persian)]. Iran Jf Diab Metabol (IJDLD). 2016; 16(1):49-62. http://ijdld.tums.ac.ir/article-1-5489-fa.html

[26] Ebrahimi A, Bolhari J, Zolfaghari F. [Stress coping strategies and social support in depressive veterans with spinal cord injury (Persian)]. Iran J Psychiatr Clin Psychol (IJPCP) 2002; 8(2):40-8. http://ijpcp.iums.ac.ir/article-1-235-fa.html

[27] Bakhshaei NM, Birashk B, Atef Vahid MK, Bolhari J. [Relationship between perceived social support and stressful life events and depression (Persian)]. Iran J Psychiatr Clin Psychol (IJPCP). 2003; 9(2):49-55. http://ijpcp.iums.ac.ir/article1-190-fa.html

[28] Panaghi L, Ghahari SH, Ahmadabadi Z, Yoosefi H. [Spouse abuse and mental Health: The role of social support and coping strategies (Persian)]. J Iran Psychol. 2008; 5(17):69-79. http://jip.azad.ac.ir/article_512364.html

[29] Akouchekian SH, Roohafza H, Hasan Zadeh A, Mohammad Sharifi H. [Relation between social support and coping with stress in nurses in psychiatric ward (Persian)]. J Guilan Uni Med Sci. 2009; 18(69):41-6. http://journal.gums.ac.ir/ article-1-266-fa.html
[30] Kalbfleisch M, Cyr A, Gregorio N, Nyhof-Yong J. Investigating coping strategies and social support among Canadian melanoma patients: A survey approach. Can Oncol Nurs J. 2015; 25(1):60-72. [DOI:10.5737/236880762516065] [PMID]

[31] Bahrami B, Bahrami A, Mashhadi A, Kareshki H. [The role of cognitive emotion-regulation Strategies in the quality of life ofcancer patients (Persian)]. J Mashhad Uni Med Sci. 2015; 58(2):96-105. [DOI: 10.22038/MJMS.2015.4370]

[32] Montazeri A, Sajadian A, Ebrahimi M, Haghighat S, Harirchi I. Factors predicting the use of complementary and alternative therapies among cancer patients in Iran. Eur J Cancer Care (Engl). 2007; 16(2):144-9. [DOI:10.1111/j.13652354.2006.00722.x] [PMID]

[33] Research Center of Management, Policy and Economics of Health, Document of Kerman Province Health Development. [Analysis of the current situation and strategies, a joint project between Kerman Governor and Kerman University of Medical Sciences and Health Services (Persian)] [Internet] 2017. [Ubdated June 2017]. Available from: http://kmu.ac.ir/Images/UserFiles/994/file/report.pdf

[34] Sherbourne CD, Stewart AL. The MOS social support survey. Social Science \& Medicine. 1991; 32(6):705-14 [DOI:10.1016/0277-9536(91)90150-B] [PMID]

[35] Garousi S, Safizadeh H, Samadian F. The study of relationship between social support and quality of life among elderly people in Kerman. Jundishapur Sci Med J. 2012; 11(3):303-15.

[36] Devaus DA. Surveys In Social Research. [Nayebi H, Persian trans]. Tehran: Nashr-e Nei Publishing; 2006.

[37] Miller D. Guide for the evaluation and social research. [Nayebi H, Persian trans.]. Tehran: Nashr-e Nei Publishing; 2001.

[38] Hassanzadeh P, Aliakbari Dehkordi M, Khamseh M.[The study of the relationship of social support and coping strategies in patients with diabetes type 2 (Persian)]. J Health Psychology. 2012; 1(2):12-21. http://hpj.journals.pnu.ac.ir/article_336.html

[39] Narimani M, RafighIrani S. [The relationship between methods of coping and mental health in patients treated with hemodialysis (Persian)]. J Princ Ment Health. 2008; 10(2):117-22. [DOI: 10.22038/JFMH.2008.1765]

[40] Tan M, Karabulutlu E. Social support and hopelessness in Turkish patients with cancer. Cancer Nurs. 2005; 28(3):236-40. [DOI:10.1097/00002820-200505000-00013] [PMID] 